\title{
Non-invasive imaging of carotid arterial restenosis using 3T cardiovascular magnetic resonance
}

\author{
Alistair C Lindsay ${ }^{1 *}$, Luca Biasiolli, ${ }^{1,2}$, Steven Knight ${ }^{1}$, Colin Cunnington ${ }^{1}$, Matthew D Robson ${ }^{1,2}$, Stefan Neubauer ${ }^{1}$, \\ James Kennedy ${ }^{3}$, Ashok Handa ${ }^{4}$ and Robin P Choudhury ${ }^{1,2}$
}

\begin{abstract}
Background: Restenosis of the carotid artery is common following carotid endarterectomy, but analysis of lesion composition has mostly been based on histological study of explanted restenotic lesions. This study investigated the ability of $3 \mathrm{~T}$ cardiovascular magnetic resonance (CMR) to determine the components of recurrent carotid artery disease and examined whether these differed from primary atherosclerotic plaque.

Methods: 50 patients underwent 3T CMR of both carotid arteries using a standard multicontrast protocol: time-of-flight (TOF), T1-weighted (T1W), T2-weighted (T2W), and PD-weighted (PDW) Turbo-Spin-Echo (TSE) sequences. 25 patients had previously undergone carotid endarterectomy (mean time since surgery 1580 days, range 45-6560 days), and 25 with primary asymptomatic atherosclerotic plaques served as controls. Two experienced reviewers analysed the multicontrast CMR images according to the presence or absence of major plaque features and assigned an overall classification type.
\end{abstract}

Results: In patients with recurrent carotid disease following endarterectomy, the mean degree of restenosis was 51\% (range 30-90\%). Three distinct types of restenosis were identified: 5 patients (20\%) showed CMR characteristics of fibro-atheromatous tissue, 11 patients (44\%) had plaque features consistent with possible myointimal (fibromuscular) hyperplasia, and 6 patients (24\%) had recurrent plaque suggestive of further lipid accumulation. Three patients (12\%) showed evidence of post-surgical dissection of the carotid intima. Compared to primary atherosclerotic plaques, restenotic plaques were more likely to contain fibro-atheromatous tissue $(p=0.05)$ and smooth muscle $(p<0.01)$, and less likely to contain lipid $(p<0.01)$. Composition did not differ significantly between patients with early and late restenosis.

Conclusions: As defined by CMR, restenotic lesions of the carotid artery fall into three distinct types and differ in composition from primary atherosclerotic plaques. If validated by subsequent histological studies, these findings could suggest a role for CMR in detecting high-risk (i.e. lipid-rich) restenotic lesions.

Keywords: Atherosclerosis, Cardiovascular magnetic resonance, Carotid plaque imaging, Carotid arteries, Restenosis

\section{Background}

Restenosis of the carotid artery is common after carotid endarterectomy (CEA). Previous ultrasound studies have reported that restenosis can occur in approximately $10 \%$ of patients within the first year following CEA, with up to $37 \%$ of patients developing restenosis in the longer term [1], however more recent estimates have been lower [2]. Despite this, there is currently no consensus on the

\footnotetext{
* Correspondence: alistair.lindsay@btinternet.com

'Oxford Centre for Clinical Magnetic Resonance Research (OCMR), Cardiovascular Medicine Division, Raddliffe Department of Medicine, University of Oxford, John Radcliffe Hospital, Oxford OX3 9DU, UK Full list of author information is available at the end of the article
}

treatment of carotid restenosis. Apparently low rates of recurrent cerebrovascular events have led some centres away from repeat intervention [3]. Conversely, other authors have advocated that restenotic plaques should be treated by repeat carotid endarterectomy [4-6], or by carotid stenting [7-10].

Contributing to this management dilemma, histological studies performed to date have revealed that restenotic lesions of the carotid artery can show markedly different compositional features [11-15]. Cossman et al. identified that restenosis early after endarterectomy can largely be attributed to myointimal hyperplasia [16]. Importantly, 
these authors also highlighted that repeat surgery for this type of recurrent disease is technically difficult and unlikely to lead to a reduction in symptoms. In contrast, late recurrent disease of the carotid artery has been shown to be histologically more similar to primary atherosclerotic plaque; in particular, a large lipid core is more commonly seen in patients with symptomatic recurrent disease several years after endarterectomy [14]. These plaques may therefore present a greater clinical risk and may necessitate further carotid surgery, despite the increased risks and technical challenges associated with a repeat procedure.

However, tissue studies can give no information on restenotic plaques that are not deemed to need surgery. Multicontrast cardiovascular magnetic resonance (CMR) of the carotid artery is a well-established method of characterising atherosclerotic plaque morphology and composition [17], fibrous cap rupture [18], and lipid-rich core in native disease $[19,20]$. However, other than a recent paper describing three case reports [21], CMR has not previously been used to characterise restenosis of the carotid artery. Therefore the aims of this study were to apply CMR to characterise recurrent carotid plaque disease (restenosis), both early and late after endarterectomy, and to compare the features of recurrent carotid disease with primary atherosclerotic plaque in a control cohort.

\section{Methods}

\section{Study population}

50 patients were recruited from the database of the vascular ultrasound scanning laboratory at the John Radcliffe Hospital, Oxford. 25 patients had previously undergone carotid endarterectomy (mean time since surgery 1580 days, range 45-6560 days) and had subsequently been found to have restenosis (range 10-90\%) at follow-up duplex ultrasonography. A further 25 patients with asymptomatic primary atherosclerotic plaque, matched for the degree of stenosis seen on ultrasound, were recruited as controls. Following an initial approach by letter, all patients gave written consent to participate in the study, which was approved by the regional ethics committee (Oxfordshire committee). All duplex ultrasound scanning was performed by a registered vascular scientist using a standard protocol to assess the common, internal, and external carotid arteries bilaterally. In addition to visual estimates of stenosis, Doppler flow velocities were used to estimate stenoses as follows: $\geq 130 \mathrm{~cm} / \mathrm{s},>50 \%$; $>180 \mathrm{~cm} / \mathrm{s}$, $>65 \%$; $>230 \mathrm{~cm} / \mathrm{s},>70 \%$; $>300 \mathrm{~cm} / \mathrm{s},>80 \%$ [22].

\section{Scan protocol}

All patients underwent 3T CMR using a standard multicontrast protocol, composed of time-of-flight (TOF), T1-weighted (T1W), T2-weighted (T2W), and PD-weighted (PDW) Turbo-Spin-Echo (TSE) sequences, to image
$10 \mathrm{~mm}$ either side of the carotid bifurcation of the index artery. Black-blood cross-sectional images of carotid arteries were acquired with 4-channel phased-array carotid coils (Machnet, Netherlands) using Double-InversionRecovery (DIR) preparation and cardiac gating. Chemical shift selective fat saturation was used to suppress the signal from subcutaneous and perivascular fat. If necessary, a saturation band was positioned on the anterior region of the neck to reduce ghosting artefacts from breathing and swallowing. Gadolinium-based contrast $(0.1 \mathrm{mmol} / \mathrm{kg})$ was only used for restenosis patients who were able to tolerate the full scan protocol (TOF, T1, T2, and PDweighted images) with ease and where the estimated Glomerular Filtration Rate (eGFR) was $>60 \mathrm{ml} /$ minute. Scan protocols were as follows: all $\mathrm{T} 1 \mathrm{~W}(\mathrm{TE}=14 \mathrm{~ms}$, $\mathrm{TR}=1 \mathrm{R}-\mathrm{R}$ interval and echo train length $\mathrm{ETL}=9$ ), $\mathrm{T} 2 \mathrm{~W}(\mathrm{TE}=89 \mathrm{~ms}, \mathrm{TR}=2 \mathrm{R}-\mathrm{R}$ and $\mathrm{ETL}=15)$ and PDW $(\mathrm{TE}=14 \mathrm{~ms}, \mathrm{TR}=2 \mathrm{R}-\mathrm{R}$ and ETL $=9)$ TSE images had slice thickness $=2 \mathrm{~mm}, \mathrm{FOV}=150 \times 150 \mathrm{~mm}^{2}$ and matrix size $=320 \times 320$ (after zero-padding was $640 \times 640$ with pixel size $=0.234 \mathrm{~mm}$ ); TOF angiography was acquired using 3D Fast Low Angle Shot (FLASH) with flip angle $=18^{\circ}, \mathrm{TR}=72 \mathrm{~ms}$, TE $=4.1 \mathrm{~ms}$, FOV $=$ $200 \times 150 \mathrm{~mm}^{2}$, matrix size $=256 \times 192$ and slice thickness $=1 \mathrm{~mm}$.

\section{Plaque analysis}

Two experienced reviewers (A.L. and L.B.) - both of whom were blinded to the patients' surgical status analysed the multicontrast CMR images (excluding any post-gadolinium images) and recorded the presence or absence of the following plaque features: intra-plaque haemorrhage, calcium, lipid, and fibrous tissue as described in previous studies [19]. Calcification is characterized by very low proton density which produces hypointense signal compared to the adjacent sternocleidomastoid muscle on all weightings. Intra-plaque haemorrhage is identified by hyperintensity on T1W and TOF images and iso- to hyperintensity on T2W and PDW images (depending on the age of the haemorrhage). Fibrous tissue is hypointense on TOF and isointense on the other weightings. Lipid-rich necrotic core has a shorter $\mathrm{T} 2$ relaxation time than fibrous tissue and the sternocleidomastoid muscle [23] and so is recognisable by hypointense signal on $\mathrm{T} 2 \mathrm{~W}$, whereas it appears isointense on all other weightings. The possible presence of myointimal hyperplasia was indicated by isointense signal relative to the surrounding tissues on all weightings [24]. Fibrous cap was assessed as defined by Hatsukami et al. [18]. An overall (predominant) phenotype (lipid-rich, fibro-atheromatous, hyperplasia) was assigned to each artery according to which plaque feature occupied the most slices. Plaques were then separated into two main groups depending on the time since carotid endarterectomy; 'early' restenosis related to those patients 
who had undergone surgery in the previous 4 years, while 'late' restenosis referred to patients who had surgery $>4$ years previously.

\section{Statistical analysis}

Continuous variables were compared using the unpaired Student $t$ test where appropriate. All continuous variables were tested for normal distribution using the ShapiroWilk test, and if necessary analysis was performed using nonparametric tests (Mann-Whitney rank sum test or the Kruskal-Wallis tests, as appropriate). Differences in characteristics between groups were compared using chi-square analysis and Fisher's exact test. A p-value $<0.05$ was considered to be significant.

\section{Results}

\section{Clinical data}

The mean age of the group with recurrent carotid disease was 71 years and 4 of the 25 patients scanned (16\%) were female. In the control group the mean age was higher (78 years, $\mathrm{p}=0.01$ ) and 8 patients were female $(32 \%, \mathrm{p}=0.32)$ (Table 1). All patients had risk factors associated with atherosclerotic disease, and the degree of carotid stenosis as measured by ultrasound was similar in both patient groups ( $51 \%$ vs. $49 \%$; $\mathrm{p}=0.93)$. More patients in the recurrent carotid disease group were smokers ( $p=0.03$ ), however no other significant differences in the risk profiles between the two groups was noted.

\section{Imaging of the carotid artery post-endarterectomy}

The mean degree of restenosis as measured by ultrasound was $51 \%$ (range 10-90\%). Three patients with restenosis $<30 \%$ showed essentially normal arterial wall features on CMR (Figure 1). In the remaining patients, all with recurrent disease of the carotid artery causing $30 \%$ stenosis or greater, three distinct imaging patterns were noted. Six patients (24\%) had recurrent plaque that

\section{Table 1 Comparison of clinical characteristics between the restenotic and primary atherosclerotic plaque (control) groups}

\begin{tabular}{lccc}
\hline & Restenosis & Controls & p-value \\
\hline Mean age (years) & 71 & 78 & 0.01 \\
Mean percentage stenosis & $51 \%$ & $49 \%$ & 0.93 \\
Female gender & $16 \%$ & $32 \%$ & 0.32 \\
Hypertension & $80 \%$ & $72 \%$ & 0.74 \\
Diabetes & $12 \%$ & $28 \%$ & 0.29 \\
Smoker & $84 \%$ & $52 \%$ & 0.03 \\
Previous myocardial infarction & $28 \%$ & $16 \%$ & 0.50 \\
Previous CABG & $16 \%$ & $8 \%$ & 0.67 \\
Treated lipids & $76 \%$ & $68 \%$ & 0.75 \\
Previous atrial fibrillation & $4 \%$ & $8 \%$ & 1.00 \\
\hline
\end{tabular}

was predominantly isointense to sternocleidomastoid on T1W and relatively hypointense on T2W, suggesting lipid accumulation (Figure 2). Five (20\%) patients had recurrent carotid disease that was isointense with the sternocleidomastoid muscle on T1W, darker on TOF imaging, and isointense on T2W and PDW, suggestive of a predominance of fibro-atheromatous tissue in the arterial wall (Figure 3). Eleven (44\%) patients showed evidence of arterial narrowing characterised by tissue that was largely isointense with the surrounding soft-tissues on all weightings, suggestive of possible myointimal hyperplasia (Figure 4). In addition, three patients (12\%) showed evidence of postsurgical dissection of the carotid intima, as suggested by a line of tissue crossing the arterial lumen that showed increased signal intensity in response to gadolinium contrast (Figure 5).

\section{Comparison of recurrent carotid disease with primary atherosclerotic plaque}

A comparison of the CMR features of recurrent carotid plaque compared to primary atherosclerotic plaque is shown in Table 2. While the presence of a thin fibrous cap, intra-plaque haemorrhage, and calcification were numerically more common in the primary atherosclerotic plaque group, these changes did not reach statistical significance overall. In contrast, fibrous tissue was more prevalent in the restenosis group ( $20 \%$ vs. $0 \% ; \mathrm{p}=0.05)$. Furthermore, when compared to primary plaques, restenotic lesions were less likely to contain lipid ( $24 \%$ vs. $80 \%$; $\mathrm{p}<0.01$ ), and more likely to show signs of myointimal hyperplasia (44\% vs. $0 \%$; $\mathrm{p}<0.01)$. Comparison between plaques imaged early and late after endarterectomy revealed no statistically significant differences in plaque composition according to time since surgery. In particular, both myointimal hyperplasia ( $42 \%$ vs. $46 \%)$ and lipid (17\% vs. $31 \%$ ) were noted in restenotic lesions imaged both early and late after surgery.

\section{Discussion}

This manuscript describes the use of 3T MRI to characterise carotid artery restenosis. The results identify three main types of recurrent carotid arterial disease following endarterectomy: lipid-rich, fibro-atheromatous, and a third subgroup with possible myointimal hyperplasia. Furthermore, this in vivo study confirms that the morphological features of recurrent carotid disease differ from those of primary atherosclerotic plaque. However, no significant difference was noted between the composition of restenotic plaque in those patients imaged early and late after surgery. The results suggest that characterisation of restenotic plaques by CMR may be of future clinical use.

Currently, no consensus exists for the management of restenosis of the carotid artery following carotid endarterectomy [25], and neither clinical follow-up nor 

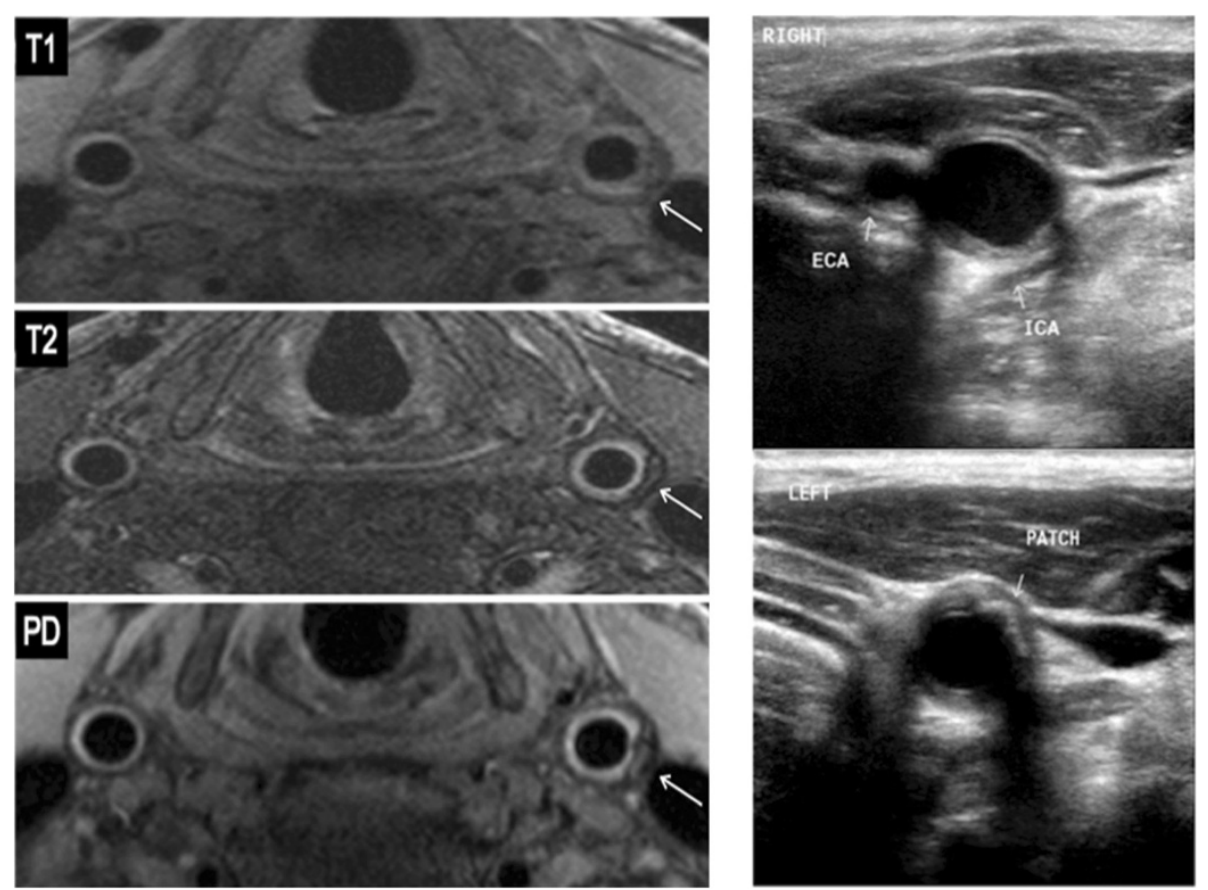

Figure 1 Patient with bilateral carotid endarterectomy five and a half years previously (2038 days); T1, T2 and PD weighting of both common carotid arteries shown (left). The right common carotid artery demonstrates a normal post-operative appearance, both on CMR and ultrasound (top right). However, a 30\% restenosis of the left common carotid was noted on ultrasound (bottom right), which was seen as a crescent of predominantly low signal surrounding the artery on CMR (white arrows).
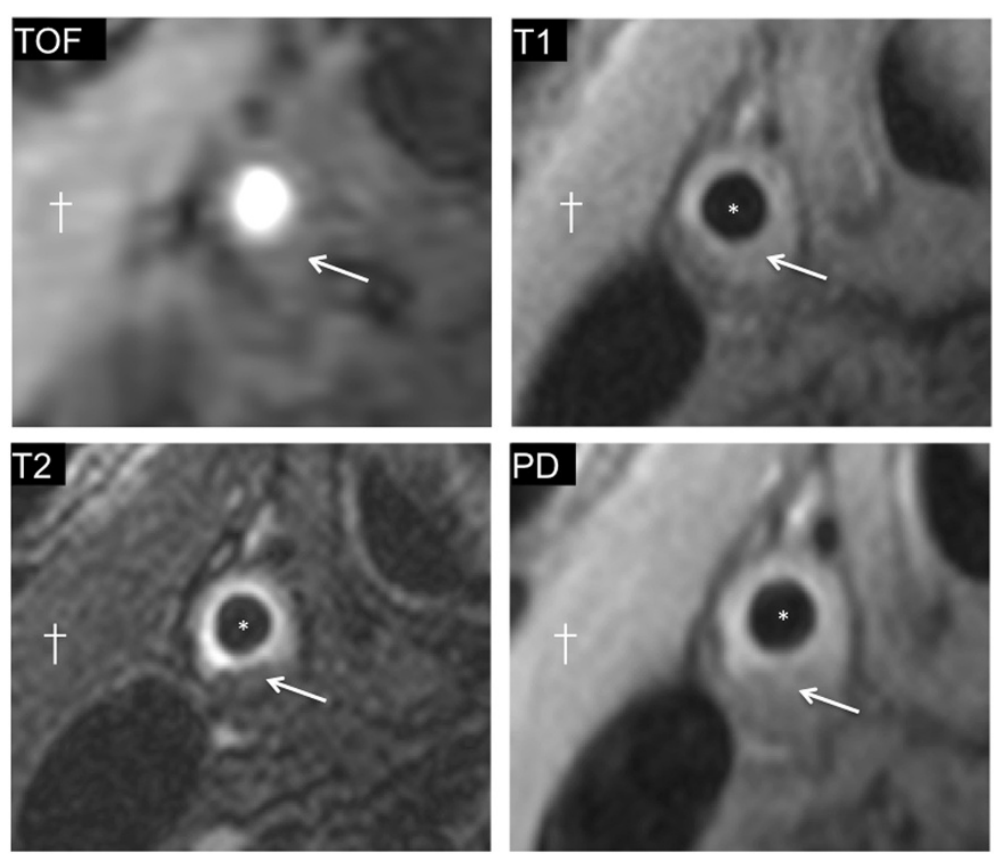

Figure 2 Example of restenosis with the appearances of lipid reaccumulation. $50 \%$ restenosis of the right common carotid artery is shown ( ${ }^{*}$ marks lumen). A crescent of plaque is seen that is isointense to the adjacent sternocleidomastoid muscle ( + ) on the T1W image (arrow). The same area shows low intensity signal on the T2W image (arrow), suggestive of lipid-rich plaque. 

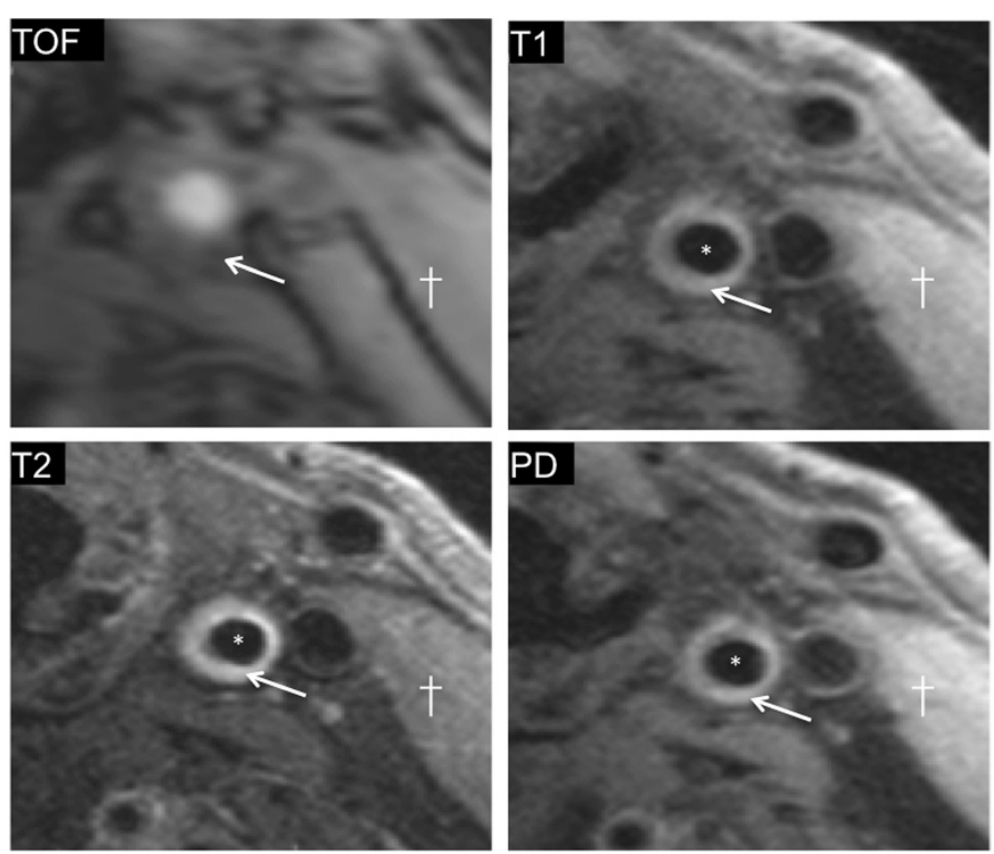

Figure 3 Example of restenosis due to possible fibro-atheromatous narrowing. 50\% restenosis of the left internal carotid artery imaged 4 years after surgery is shown. The signal appears hypointense on TOF images (arrow), but isointense signal is seen from the tissue surrounding the lumen $\left(^{*}\right.$ ) on the T1W image (arrow); the signal is similar in intensity to that from the adjacent sternocleidomastoid muscle. Similarly, on PDW images (arrow) the signal appears to be isointense compared to sternocleidomastoid ( $t$ ), suggestive of fibrous tissue deposition.
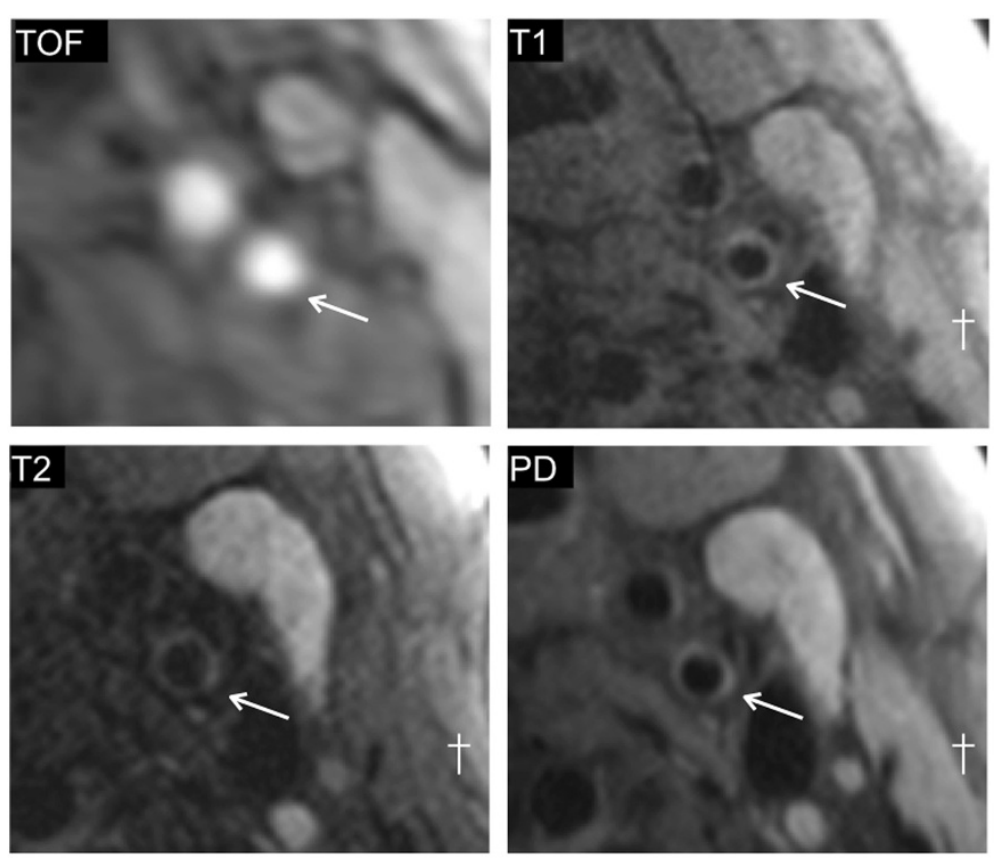

Figure 4 Example of restenosis due to possible myointimal hyperplasia. $65 \%$ restenosis of the left internal carotid artery 4 months following surgery is shown (*marks lumen, + marks sternocleidomastoid). The signal intensity seen from the arterial wall is comparable to that of the surrounding tissues on all four weightings. 


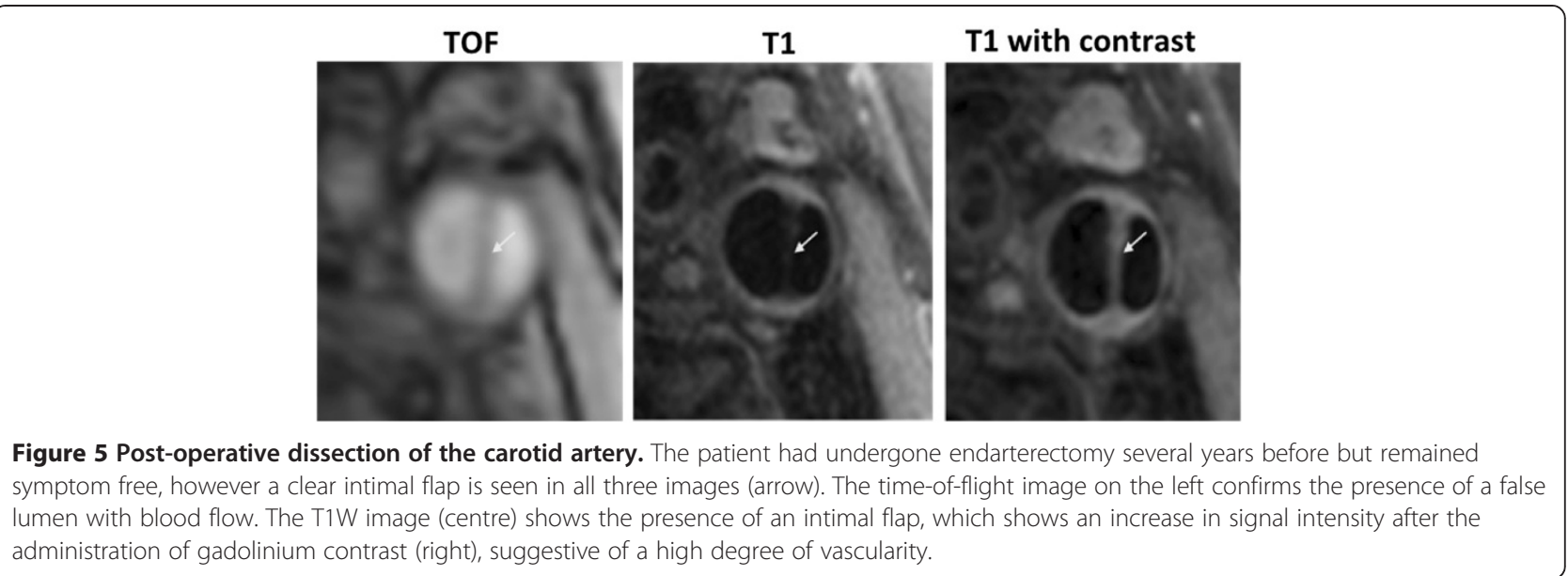

surveillance imaging with ultrasound have been shown to improve clinical outcomes postoperatively [26]. Indeed, at present even the optimal timing of imaging of the carotid artery following endarterectomy is not agreed [27-29] although ultrasound follow-up is the most commonly used. However, although histological studies have shown the variable composition of restenotic lesions, ultrasound is often unable to provide detailed information on plaque composition; for example, in the early stages following surgery, recurrent plaque appears universally isoechoic [30]. A previous study of four patients undergoing popliteal artery angioplasty demonstrated the ability of CMR to show arterial remodelling, but did not give any information on restenotic plaque [31]. The results described here show that, using standard sequences, high-resolution $3 \mathrm{~T}$ CMR can potentially give additional information on the composition of recurrent carotid plaque, which could allow for differentiation of relatively benign types of restenotic plaque (e.g. myointimal hyperplasia) from potentially more dangerous (e.g. lipid laden) plaque.

The relationship between traditional atherosclerosis risk factors and arterial restenosis remains a subject of debate, however smoking is considered to be the factor most predictive of restenosis [1]. This is in keeping with the findings of this analysis, which found that $84 \%$ of patients with restenosis had a history of smoking (Table 1). Age and sex have also been suggested as potential predictors of restenosis, and in this study patients with restenosis were found to be younger and more likely to be male (Table 1).

Previous histological studies examining the nature of carotid restenosis following repeat surgery have tended to be small. However, several such studies have suggested that the composition of recurrent carotid atherosclerosis varies according to the time that it develops. Whereas most cases of early restenosis (generally defined as restenosis within four years of surgery) show marked accumulation of smooth muscle cells and fibro-atheromatous tissue, restenosis that occurs after four years more closely resembles primary atherosclerotic plaque in that it generally contains far more lipid [14]. Although our study also noted that fibro-atheromatous tissue was more common in early restenosis, and lipid-rich plaque was more common in late stenosis, overall no statistically significant difference in plaque composition was noted between early and late lesions. There are several possible explanations for this observation. Firstly, histological studies are inherently biased towards patients in whom surgery was undertaken and excludes patients managed conservatively. This

Table 2 Comparison of plaque components between primary and restenotic plaques

\begin{tabular}{|c|c|c|c|c|c|}
\hline & & Restenotic $\mathrm{F}$ & & Primary plaque & $P$ value (Primary vs. \\
\hline & All & Early & Late & & \\
\hline & & ( $<4$ years) & (>4 years) & & \\
\hline Fibrous cap ${ }^{*}$ & $8 \%$ & $8 \%$ & $8 \%$ & $24 \%$ & 0.25 \\
\hline Haemorrhage & $8 \%$ & $0 \%$ & $15 \%$ & $24 \%$ & 0.25 \\
\hline Calcium & $0 \%$ & $0 \%$ & $0 \%$ & $8 \%$ & 0.49 \\
\hline Lipid & $24 \%$ & $17 \%$ & $31 \%$ & $80 \%$ & $<0.01$ \\
\hline Fibrous tissue & $20 \%$ & $25 \%$ & $15 \%$ & $0 \%$ & 0.05 \\
\hline Myointimal hyperplasia & $44 \%$ & $42 \%$ & $46 \%$ & $0 \%$ & $<0.01$ \\
\hline
\end{tabular}

* $=$ No cases of fibrous cap rupture were seen. 
might be expected to lead to an over-representation of severe or symptomatic restenosis lesions, which are commonly lipid-rich. Secondly, histological studies have taken the time from operation to recurrence to make the distinction between 'early' and 'late' restenosis. In our cross-sectional study patients with apparently 'late' disease may have developed a recurrent lesion at an earlier stage, but with later recruitment. Lastly, while this study was able to detect differences in composition between native and restenotic lesions (below), a larger sample size may be required to detect more subtle withingroup differences.

This in vivo study identifies important differences in the nature of restenotic - as opposed to primary - carotid atherosclerotic plaques that have only previously been described in histological examination of explanted tissue. Although many plaque features are common to both primary and recurrent disease, we found a higher prevalence of lipid-rich lesions in patients with primary atherosclerosis ( $80 \%$ vs. $24 \%, \mathrm{p}<0.01$ ) compared to restenotic lesions (Figure 2). A separate type of restenosis showed appearances consistent with fibro-atheromatous disease (Figure 3). A third group of patients had significant restenosis characterised by a signal intensity that was similar to that of the surrounding tissues on T1, T2, and PD weightings (Figure 4), a finding which was not seen in the primary atherosclerotic plaque group $(0 \%$ vs. $44 \%, \mathrm{p}<0.01)$. These signal characteristics were the most common finding in the early restenosis patients, a group in which myointimal hyperplasia caused by smooth muscle hypertrophy is known to be the most frequent cause of restenosis and calcification is rarely seen. Indeed, a histological analysis by Hellings et al. found that $100 \%$ of restenotic plaques occurring less than two years after endarterectomy contained smooth muscle cells and collagen; none contained calcium [14].

Lastly, three patients were noted to have developed post-endarterectomy dissection of the internal carotid artery. This complication of carotid artery surgery has previously been thought to be relatively rare [32], however it may be that current screening methods are poor at detecting its presence. It is important to be aware of this complication, as patients with asymptomatic internal carotid artery dissections may present with clinical symptoms months, or even years, later [33]. As such, the detection of this complication represents another potential benefit of using CMR post-endarterectomy.

\section{Conclusions}

We have described the use of CMR to differentiate different types of carotid arterial restenosis in vivo. CMR of carotid restenosis is capable of giving detailed information on the composition of restenotic plaque and in addition may detect post-operative complications, such as internal carotid artery dissection. Further longitudinal studies with histological verification will be needed to confirm these findings and investigate the relationship between restenotic plaque appearances and the development of cerebrovascular events.

\section{Competing interests}

There are no competing interests.

\section{Authors' contributions}

$A C L$ recruited and imaged the study participants, analysed the data, and wrote the manuscript. LB assisted with imaging study participants, analysed the data, and revised the manuscript. SK assisted with imaging the study participants and revised the manuscript. CC assisted with imaging the study participants and revised the manuscript. MDR assisted with imaging and revised the manuscript. SN revised the manuscript. JK revised the manuscript. AH assisted with recruitment and revised the manuscript. RPC revised the manuscript. All authors read and approved the final manuscript.

\section{Authors' information}

Joint senior author: Ashok Handa and Robin P Choudhury.

\section{Author details}

${ }^{1}$ Oxford Centre for Clinical Magnetic Resonance Research (OCMR), Cardiovascular Medicine Division, Radcliffe Department of Medicine, University of Oxford, John Radcliffe Hospital, Oxford OX3 9DU, UK. ${ }^{2}$ Oxford Acute Vascular Imaging Centre (AVIC), Radcliffe Department of Medicine, University of Oxford, John Radcliffe Hospital, Oxford OX3 9DU, UK. ${ }^{3}$ Investigative Medicine Division, Radcliffe Department of Medicine, University of Oxford, John Radcliffe Hospital, Oxford OX3 9DU, UK. ${ }^{4}$ Nuffield Department of Surgical Sciences, University of Oxford, John Radcliffe Hospital, Oxford OX3 9DU, UK.

Received: 23 September 2013 Accepted: 27 December 2013 Published: 8 January 2014

\section{References}

1. Lattimer CR, Burnand KG. Recurrent carotid stenosis after carotid endarterectomy. Br J Surg. 1997; 84:1206-19.

2. Lal BK, Beach KW, Roubin GS, Lutsep HL, Moore WS, Malas MB, Chiu D, Gonzales NR, Burke JL, Rinaldi M, Elmore JR, Weaver FA, Narins CR, Foster M, Hodgson KJ, Shepard AD, Meschia JF, Bergelin RO, Voeks JH, Howard G, Brott TG, CREST Investigators. Restenosis after carotid artery stenting and endarterectomy: a secondary analysis of CREST, a randomised controlled trial. Lancet Neurol. 2012; 11:755-63.

3. Healy DA, Zierler RE, Nicholls SC, Clowes AW, Primozich JF, Bergelin RO, Strandness DE. Long-term follow-up and clinical outcome of carotid restenosis. J Vasc Surg. 1989; 10:662-8. discussion 668-9.

4. Harris RA, Stow N, Fisher CM, Neale ML, Appleberg M. Carotid redo surgery: both safe and durable. ANZ J Surg. 2003; 73:1000-3.

5. O'Donnell TF, Rodriguez AA, Fortunato JE, Welch HJ, Mackey WC. Management of recurrent carotid stenosis: should asymptomatic lesions be treated surgically? J Vasc Surg. 1996; 24:207-12.

6. Abou-Zamzam AM, Moneta GL, Landry GJ, Yeager RA, Edwards JM, McConnell DB, Taylor LM, Porter JM. Carotid surgery following previous carotid endarterectomy is safe and effective. Vasc Endovascular Surg. 2002; 36:263-70.

7. New G, Roubin GS, Iyer SS, Vitek JJ, Wholey MH, Diethrich EB, Hopkins LN, Hobson RW, Leon MB, Myla SV, Shawl F, Ramee SR, Yadav JS, Rosenfield K, Liu MW, Gomez CR, Al-Mubarak N, Gray WA, Tan WA, Goldstin JE, Stack RS. Safety, efficacy, and durability of carotid artery stenting for restenosis following carotid endarterectomy: a multicenter study. J Endovasc Ther. 2000; 7:345-52.

8. Hernandez-Vila E, Strickman NE, Skolkin M, Toombs BD, Krajcer Z. Carotid stenting for post-endarterectomy restenosis and radiation-induced occlusive disease. Texas Heart Ins J Texas Heart Ins of St Luke"s Episcopal Hosp, Texas Child" Hosp. 2000; 27:159-65.

9. Yadav JS, Roubin GS, King P, lyer S, Vitek J. Angioplasty and stenting for restenosis after carotid endarterectomy. Initial experience. Stroke. 1996; 27:2075-9. 
10. de Borst GJ, Ackerstaff RGA, De Vries J-PPM, van der Pavoordt ED, Vos JA, Overtoom TT, Moll FL. Carotid angioplasty and stenting for postendarterectomy stenosis: long-term follow-up. J Vasc Surg. 2007; 45:118-23.

11. Thomas M, Otis SM, Rush M, Zyroff J, Dilley RB, Bernstein EF. Recurrent carotid artery stenosis following endarterectomy. Ann Surg. 1984; 200:74-9.

12. Clagett GP, Rich NM, McDonald PT, Salander JM, Youkey JR, Olson DW, Hutton JE. Etiologic factors for recurrent carotid artery stenosis. Surgery. 1983; 93:313-8.

13. Clagett GP, Robinowitz M, Youkey JR, Fisher DF, Fry RE, Myers SI, Lee EL, Collins GJ, Virmani R. Morphogenesis and clinicopathologic characteristics of recurrent carotid disease. J Vasc Surg. 1986; 3:10-23.

14. Hellings WE, Moll FL, De Vries JPPM, de Bruin P, De Kleijn DPV, Pasterkamp $G$. Histological characterization of restenotic carotid plaques in relation to recurrence interval and clinical presentation: a cohort study. Stroke. 2008; 39:1029-32.

15. Marek JM, Koehler C, Aguirre ML, Westerband A, Gentile AT, Mills JL, Hunter GC. The histologic characteristics of primary and restenotic carotid plaque. J Surg Res. 1998; 74:27-33.

16. Cossman D, Callow AD, Stein A, Matsumoto G. Early restenosis after carotid endarterectomy. Arch Surg. 1978; 113:275-8.

17. Cai JM, Hatsukami TS, Ferguson MS, Small R, Polissar NL, Yuan C. Classification of human carotid atherosclerotic lesions with in vivo multicontrast magnetic resonance imaging. Circulation. 2002; 106:1368-73.

18. Hatsukami TS, Ross R, Polissar NL, Yuan C. Visualization of fibrous cap thickness and rupture in human atherosclerotic carotid plaque in vivo with high-resolution magnetic resonance imaging. Circulation. 2000; 102:959-64.

19. Yuan C, Mitsumori LM, Ferguson MS, Polissar NL, Echelard D, Ortiz G, Small R, Davies JW, Kerwin WS, Hatsukami TS. In vivo accuracy of multispectral magnetic resonance imaging for identifying lipid-rich necrotic cores and intraplaque hemorrhage in advanced human carotid plaques. Circulation. 2001; 104:2051-6.

20. Saam T, Ferguson MS, Yarnykh VL, TAKAYA N, Xu D, Polissar NL, Hatsukami TS, Yuan C. Quantitative evaluation of carotid plaque composition by in vivo MRI. Arterioscler Thromb Vasc Biol. 2005; 25:234-9.

21. Endo H, Kamiyama K, Takahira K, Ogino T, Takada H, Kataoka T, Hyogo T, Nakagawara J, Ono H, Nakamura H. Carotid MRI of initial and recurrent plaques in patients with restenosis after endarterectomy: three case reports. Brain nerve $=$ Shinkei kenkyū no shinpo. 2013; 65:93-7.

22. Jahromi AS, Cinà CS, Liu Y, Clase CM. Sensitivity and specificity of color duplex ultrasound measurement in the estimation of internal carotid artery stenosis: a systematic review and meta-analysis. J Vasc Surg. 2005; 41:962-72.

23. Biasiolli L, Lindsay AC, Chai JT, Choudhury RP, Robson MD. In-vivo quantitative T2 mapping of carotid arteries in atherosclerotic patients: segmentation and T2 measurement of plaque components. J Cardiovasc Magn Reson. 2013; 15:69.

24. Ma Z-L, Teng G-J, Chen J, Zhang H-Y, Cao A-H, Ni Y. A rabbit model of atherosclerosis at carotid artery: MRI visualization and histopathological characterization. European Radiol. 2008; 18:2174-81.

25. Hobson RW, Goldstein JE, Jamil Z, Lee BC, Padberg FT, Hanna AK, Gwertzman GA, Pappas PJ, Silva MB. Carotid restenosis: operative and endovascular management. J Vasc Surg. 1999; 29:228-35. discussion 235-8.

26. Naylor AR, John T, Howlett J, Gillespie I, Allan P, Ruckley CV. Surveillance imaging of the operated artery does not alter clinical outcome following carotid endarterectomy. Br J Surg. 1996; 83:522-6.

27. Salvian A, Baker JD, Machleder HI, Busuttil RW, Barker WF, Moore WS. Cause and noninvasive detection of restenosis after carotid endarterectomy. Am J Surg. 1983; 146:29-34.

28. Ricotta JJ, DeWeese JA. Is routine carotid ultrasound surveillance after carotid endarterectomy worthwhile? Am J Surg. 1996; 172:140-2. discussion 143.

29. Frericks H, Kievit J, van Baalen JM, van Bockel JH. Carotid recurrent stenosis and risk of ipsilateral stroke: a systematic review of the literature. Stroke. 1998; 29:244-50.

30. Makihara N, Toyoda K, Uda K, Inoue T, Gotoh S, Fujimoto S, Yasumori K, Ibayashi S, lida M, Okada Y. Characteristic sonographic findings of early restenosis after carotid endarterectomy. J Ultrasound Med Off J Am Inst Ultrasound Med. 2008; 27:1345-52.
31. Coulden RA, Moss H, Graves MJ, Lomas DJ, Appleton DS, Weissberg PL. High resolution magnetic resonance imaging of atherosclerosis and the response to balloon angioplasty. Heart. 2000; 83:188-91.

32. Aggarwal S, Kucharczyk W, Keller MA. Asymptomatic postendarterectomy dissection of the internal carotid artery detected incidentally on MRI. Neuroradiology. 1993; 35:586-7.

33. Mokri B, Piepgras DG, Houser OW. Traumatic dissections of the extracranial internal carotid artery. J Neurosurg. 1988; 68:189-97.

doi:10.1186/1532-429X-16-5

Cite this article as: Lindsay et al:: Non-invasive imaging of carotid arterial restenosis using $3 \mathrm{~T}$ cardiovascular magnetic resonance. Journal of Cardiovascular Magnetic Resonance 2014 16:5.

\section{Submit your next manuscript to BioMed Central and take full advantage of:}

- Convenient online submission

- Thorough peer review

- No space constraints or color figure charges

- Immediate publication on acceptance

- Inclusion in PubMed, CAS, Scopus and Google Scholar

- Research which is freely available for redistribution

Submit your manuscript at www.biomedcentral.com/submit
C) Biomed Central 